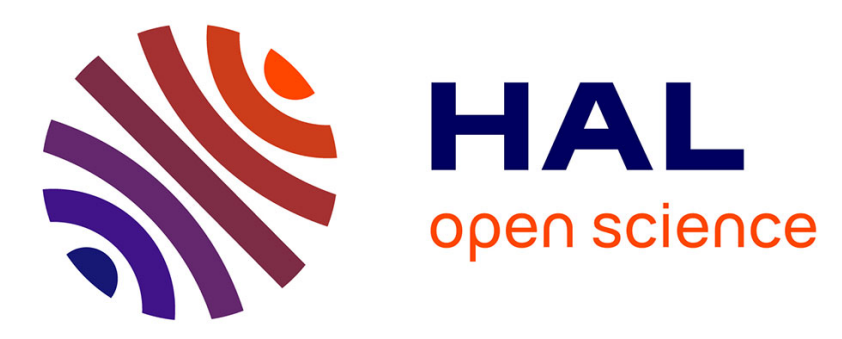

\title{
Loss decomposition in plastically deformed and partially annealed steel sheets
}

\author{
F.J.G. Landgraf, C. Ragusa, D. Luiz Rodrigues, M Botani de Souza Dias,
} Olivier de La Barrière, F Mazaleyrat, F. Fiorillo, C. Appino, L. Martino

\section{> To cite this version:}

F.J.G. Landgraf, C. Ragusa, D. Luiz Rodrigues, M Botani de Souza Dias, Olivier de La Barrière, et al.. Loss decomposition in plastically deformed and partially annealed steel sheets. Journal of Magnetism and Magnetic Materials, 2020, 502, pp.166452. 10.1016/j.jmmm.2020.166452 . hal-03000534

\section{HAL Id: hal-03000534 \\ https://hal.science/hal-03000534}

Submitted on 12 Nov 2020

HAL is a multi-disciplinary open access archive for the deposit and dissemination of scientific research documents, whether they are published or not. The documents may come from teaching and research institutions in France or abroad, or from public or private research centers.
L'archive ouverte pluridisciplinaire HAL, est destinée au dépôt et à la diffusion de documents scientifiques de niveau recherche, publiés ou non, émanant des établissements d'enseignement et de recherche français ou étrangers, des laboratoires publics ou privés. 


\title{
Loss decomposition in plastically deformed and partially annealed steel sheets
}

\author{
F. J. G. Landgraf ${ }^{1}$, C. Ragusa ${ }^{2}$, D. Luiz Rodrigues, $\mathrm{Jr}^{1}$, M. Botani de Souza Dias ${ }^{1}$, O. de la Barrière ${ }^{3}$, \\ F. Mazaleyrat ${ }^{3}$, F. Fiorillo ${ }^{4}$, C. Appino ${ }^{4}$, L. Martino ${ }^{4}$ \\ ${ }^{1}$ USP, São Paulo, SP, Brazil \\ ${ }^{2}$ Department of Energy, Politecnico di Torino, Torino 10129, Italy \\ ${ }^{3}$ Laboratoire SATIE, CNRS - ENS Cachan, F-94230 Cachan, France \\ ${ }^{4}$ Advanced Materials Metrology and Life Science Division, INRiM, Torino, Italy
}

\begin{abstract}
There is an increasing interest in the optimization of non-oriented electrical steels for applications under excitation frequencies above $400 \mathrm{~Hz}$. This paper discusses the possibility of a new manufacturing procedure where skin-pass and subsequent heat treatment for recovery are applied as the two last stages of sheet processing. Samples from a commercial non-oriented $3 \%$ silicon steel were submitted to a $2.5 \%$ thickness reduction and heat treated at temperatures ranging between 600 and $850{ }^{\circ} \mathrm{C}$ for 2 hours. It is shown that, although the hysteresis loss increases with plastic deformation, the excess loss decreases in such a way that under increasing magnetizing frequencies the total energy loss of the deformed and recovered sample becomes lower than in the starting material. The higher the annealing temperature the lower the frequency at which crossover of the loss curves occur, as long as full recrystallization does not occur. It is assumed that with the dislocation structures left in the deformed and partially recovered samples one achieves a condition of increased fragmentation of the magnetization process, that is, increased number of concurring correlation regions (Magnetic Objects). The corresponding decrease of the excess loss component can eventually overcompensate for the deterioration of the quasi-static magnetic properties and lead to lower total losses. .
\end{abstract}

Index Terms - NO steel sheets, plastic straining, annealing, loss separation

\section{INTRODUCTION}

E-mobility is placing new demands for electrical steels suitable for automotive applications. Consequently, electrical steels manufacturers have introduced some grades specially tailored for e-mobility, whose power losses are specified at $400 \mathrm{~Hz}$ and higher frequencies [1] [2]. The main trend is to offer steels with smaller thickness, smaller grain size, and high silicon content. This paper addresses the possibilities of a different approach, which consists in applying, as a final stage of electrical steel processing, a slight plastic deformation by cold rolling, followed by either partial or full recovery by annealing.

It is well known that the dislocations introduced by plastic deformation, increase coercivity and hysteresis loss [3 - 6], but it is less acknowledged that they can decrease significantly the excess loss [7]. As the hysteresis energy loss does not depend, in the absence of skin effect, on the frequency $f$ and the excess energy loss increases as $f^{1 / 2}$, it is expected that, above a certain frequency, plastically deformed samples could have lower total loss $W(f)[7,8]$. A recovery heat treatment, in which the dislocations introduced by plastic straining are reduced, but not fully eliminated, as it would happen with recrystallization, may reduce the hysteresis loss without increasing significantly the excess loss. Consequently, a frequency $f_{0}$ can be found, at which a crossover of the $W(f)$ curves of the unstrained sheets and the deformed and heat-treated ones occurs. At the same time, part of the mechanical strength induced by plastic deformation might be preserved by partial recovery [9].

We will show in the following how the energy loss and its frequency dependence upon plastic deformation and subsequent recovery can be assessed by the decomposition principle and, in particular, by identification of the competing effects of dislocations on hysteresis and excess losses.

\section{PREPARATION OF SAMPLES AND EXPERIMENTAL CHARACTERIZATION}

\section{A. Samples}

An Fe-(3wt\%)Si non-oriented (NO) sheet (thickness $0.505 \mathrm{~mm}$, resistivity $\rho=50.0 \cdot 10^{-8} \Omega \mathrm{m}$, average grain size $\langle s\rangle=91 \mu \mathrm{m}$, density $\delta=7630 \mathrm{~kg} / \mathrm{cm}^{3}$ ) provided by APERAM Brazil, was investigated. A $300 \mathrm{~mm}$ wide strip was subjected to $2.5 \%$ reduction by cold rolling, down to thickness $d=0.492 \mathrm{~mm}$. Epstein strips $(300 \times 30 \mathrm{~mm})$ were cut before and after plastic deformation. The cold-rolled strips were then annealed for two hours at five different temperatures, ranging between $600{ }^{\circ} \mathrm{C}$ and $850{ }^{\circ} \mathrm{C}$, under vacuum atmosphere. The average grain size was measured after each treatment by optical metallography. As shown in Table I, the grain size was only slightly affected by annealing up to $800{ }^{\circ} \mathrm{C}$, whereas abnormal grain growth was observed in the strips treated at $850{ }^{\circ} \mathrm{C}$. This behavior, is understood in the light of the recrystallization behavior of a sheet with rather large initial grain size that has undergone a small deformation (skin pass).

TABLE I

SAMPLE PARAMETERS

\begin{tabular}{|l|l|l|l|l|}
\hline Sample & & $\begin{array}{l}\text { Annealing temperature } T_{\mathrm{a}} \\
\left({ }^{\circ} \mathrm{C}\right)\end{array}$ & $\begin{array}{l}\text { Thickness } \\
(\mathrm{mm})\end{array}$ & $\begin{array}{l}\text { Average grain size }\langle s> \\
(\mu \mathrm{m})\end{array}$ \\
\hline
\end{tabular}




\begin{tabular}{|c|c|c|c|c|}
\hline 1 & BASE material & - & 0.505 & o1 \\
\hline 2 & COLD rolled & - & 0.492 & 91 \\
\hline 4 & \multirow{3}{*}{$\begin{array}{l}\text { COLD rolled } \\
+2 \text { hour annealing }\end{array}$} & 700 & 0.492 & 94 \\
\hline 6 & & 800 & \multirow{2}{*}{0.492} & 100 \\
\hline 7 & & 850 & & 1840 \\
\hline
\end{tabular}

One of the laws of recrystallization states that the deformation controls the size of the recrystallized grains [11, 12], so that the lighter the deformation, the larger the recrystallized grain size. The smaller the deformation, less recrystallization nuclei are created, leading to large recrystallized grains, but longer times or higher temperatures are needed for the process to be completed. Due to the same phenomenon, large grain sizes are observed at the edges of cut laminations after "stress relief treatment". This should not be confused with the conventional grain growth, as defined in the metallurgical literature. Grain growth delivers straight grain boundaries, whereas large grain sizes obtained by recrystallization always have wavy grain boundaries, as is the case in the present $850^{\circ} \mathrm{C}$ annealed samples.

The thermodynamic potential for recrystallization is the energy associated with the mechanical stresses around the dislocations created by the plastic deformation. The samples heat treated below $800{ }^{\circ} \mathrm{C}$ have dislocation structures that partly survived the recovery process. The higher the temperature, the higher the mobility of dislocations and the easier their re-organization and annihilation processes. It has been shown that the recovery process has a stronger effect on the magnetic properties than on the mechanical ones. The magnetic losses are then expected to have a relative decrease larger than the one suffered by the yield strength [11].

\section{B. Experimental setup for loss measurements}

The cut and treated NO Fe-Si samples were magnetically characterized from $2 \mathrm{~Hz}$ to $500 \mathrm{~Hz}$ by means of a single-strip tester, based on the use of a permeameter, where the strip sample is inserted between the pole faces of a double-C yoke, made of stripwound grain-oriented (GO) laminations. The adopted measuring arrangement, shown in Fig. 1, is described in detail in [13].

The measurement of the magnetic field is performed by means of an $H$-coil wound on a thin $(\sim 1 \mathrm{~mm})$ glass former, whose turn-area is determined by placing it in a reference solenoid and measuring the flux variation induced by a known current step [14]. The $H$-coil signal is amplified by low noise preamplifiers (SR560 from Stanford Research Systems). The $30 \mathrm{~mm}$ long $H$-coil, placed flat at center of the strip, is surrounded by the secondary coil. A digital feedback control system [15] is implemented, ensuring sinusoidal induction $B(t)$ at all measuring peak values $B_{\mathrm{p}}$. The energy loss is then obtained by computing the area of the hysteresis loop. To note that in the investigated $B_{\mathrm{p}}$ range, induction and polarization coincide $B(t) \equiv J(t)$.

A uniformly wound magnetizing solenoid covers the distance $L_{1}=190 \mathrm{~mm}$ between the pole faces of the soft magnetic yoke, which, having a square cross-sectional area much larger than that of the sample, ensure good flux closure and negligible additional magnetomotive force.

\section{RESULTS AND DISCUSSION}

\section{A. Loss separation and analysis}

\section{1) Energy loss versus frequency}

The energy loss was measured, up to $500 \mathrm{~Hz}$, at different $B_{\mathrm{p}}$ values $(0.5 \mathrm{~T}, 1.0 \mathrm{~T}$, and $1.5 \mathrm{~T})$ in all the samples listed in Table I. Fig. 2 shows the frequency dependence of the total magnetic loss at $B_{\mathrm{p}}=1.5 \mathrm{~T}$ for samples subjected to $2.5 \%$ reduction by cold rolling, followed by a set of annealing treatments ( 2 hours) at temperatures $T_{\mathrm{a}}$ ranging between $600{ }^{\circ} \mathrm{C}$ and $850{ }^{\circ} \mathrm{C}$. The loss measured in the undeformed sample (Sample 1) is reported as a reference. 
A progressive decrease of the energy loss at very low frequencies is observed under increasing annealing temperature. The lower limit is actually exhibited by the as-received undeformed sample (Sample 1), except for the sample annealed at $850^{\circ} \mathrm{C}$ (Sample 7), which has undergone full recrystallization and is endowed with a very large final grain size. These two samples, however, exhibit a higher rate of increase of $W(f)$ with frequency, if compared with the cold-rolled and partially recovered materials. A crossover of the $W(f)$ curve of the undeformed material with the curves of the cold-rolled samples eventually occurs, at a frequency $f_{0}$ progressively decreasing with increasing degree of recovery. We obtain, for example, that $f_{0} \sim 370 \mathrm{~Hz}$ for the deformed sample (Sample 2) and $f_{0} \sim 50 \mathrm{~Hz}$ for the sample annealed at $800{ }^{\circ} \mathrm{C}$ (Sample 6). To note, however, that $W(f)$ is always lower in the recrystallized sample (Sample 7) than in the starting material (Sample 1).

It is concluded that conditions of partial recovery, like the ones obtained in Sample $4\left(T_{\mathrm{a}}=700{ }^{\circ} \mathrm{C}\right)$, can lead to the lowest $W(f)$ value in the upper frequency range, beyond about $100 \mathrm{~Hz}$. As discussed below, this advantage comes from the decrease of the excess loss component $W_{\text {exc }}(f)$, which overcomes the increase of the hysteresis loss $W_{\text {hyst }}(f)$ with respect to the starting material (Sample 1). This effect is observed at all the investigated $B_{\mathrm{p}}$ values, with the crossover moving to somewhat higher frequencies at lower inductions.

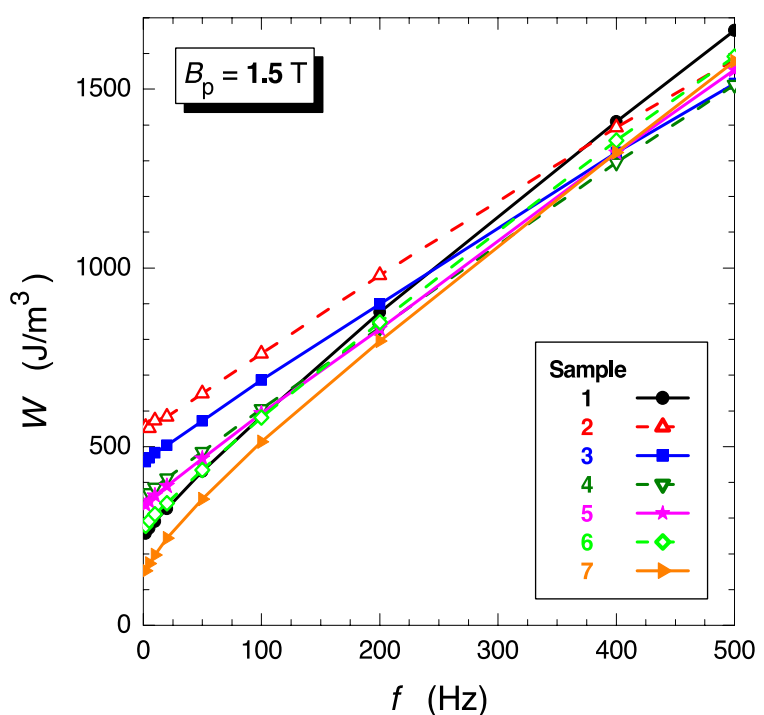

Fig. 2. Energy loss $W(f)$ versus frequency at $B_{\mathrm{p}}=1.5 \mathrm{~T}$ in NO Fe-(3 wt $\left.\%\right) \mathrm{Si}$ sheets, $2.5 \%$ reduced by cold rolling and subjected to annealing at temperatures ranging between $600{ }^{\circ} \mathrm{C}$ and $850{ }^{\circ} \mathrm{C}$. Competition between increase of hysteresis loss and decrease of excess loss leads to crossover of the $W(f)$ curves of the treated materials (except the recrystallized Sample 7) with respect to the $W(f)$ curve of the untreated reference material (Sample 1). The crossover frequency $f_{0}$ is a decreasing function of the annealing temperature $T_{\mathrm{a}}$, that is, of the degree of recovery. Sample $4\left(T_{\mathrm{a}}=700^{\circ} \mathrm{C}\right)$ exhibits the lowest loss figure beyond about $100 \mathrm{~Hz}$.

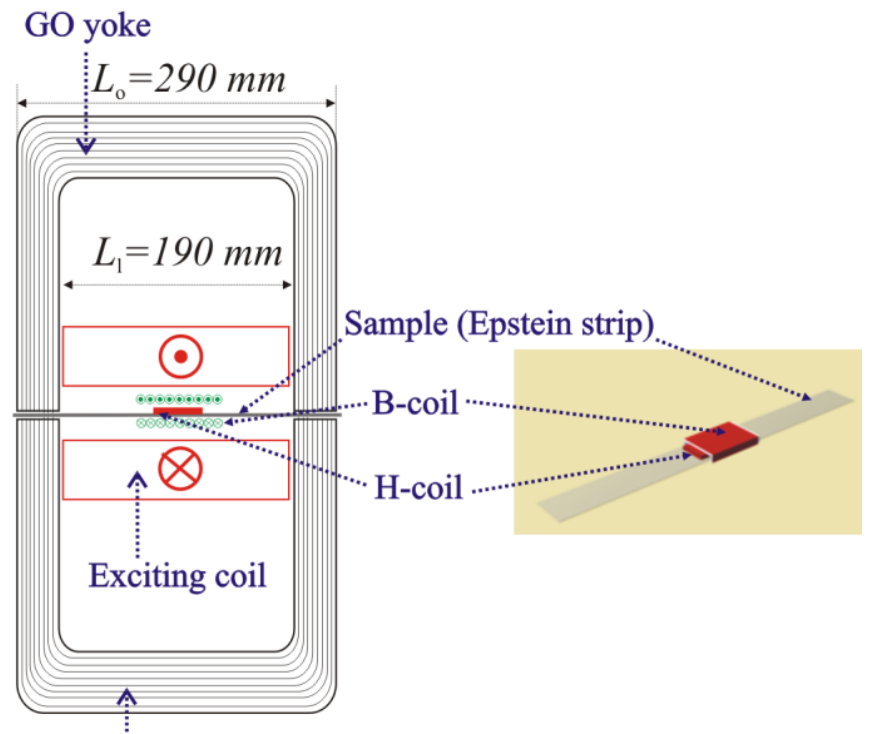

GO yoke

Fig. 1. The single-strip permeameter (adapted from [13]). The Epstein strip sample is endowed with a centrally located $H$-coil, enwrapped by a secondary $B$-coil. 


\section{2) Loss separation}

Hysteresis loss: The hysteresis loss $W_{\text {hyst }}\left(B_{\mathrm{p}}\right)$ is obtained, for each peak induction and each sample, by extrapolating the measured loss to zero frequency. The extrapolation procedure is discussed in detail in [16]. Fig. 3 shows the behavior of $W_{\text {hyst }}\left(B_{\mathrm{p}}\right)$ for the whole series of samples. By increasing the temperature of isochronal annealing, $W_{\text {hyst }}\left(B_{\mathrm{p}}\right)$ decreases in a monotonical fashion, to finally approach, for $T_{\mathrm{a}}=800^{\circ} \mathrm{C}$, the quasi-static loss figure of the untreated sample 1 . Quite smaller loss figure is eventually attained upon annealing at $850{ }^{\circ} \mathrm{C}$ and the ensuing abnormal grain growth by recrystallization. The large increase of $W_{\text {hyst }}\left(B_{\mathrm{p}}\right)$ (i.e. of the coercive field $H_{\mathrm{c}}$, as observed in Fig. 4) for the $2.5 \%$ reduction is consistent with the generally observed sharp increase of strain hardening in polycrystalline iron at low deformation values, where the work-hardening rate is the highest [17]. Stage I and II of plastic deformation are involved, where single dislocations and groups of dislocations interact through their stress field with the domain walls. Tight dislocation tangles and cells, acting as subgrains, are very unlikely to occur for a deformation of the order of $2.5 \%$ [18].

Classical loss: The loss separation is performed here under the assumption of negligible skin effect. In this case, the classical loss component is obtained versus $B_{\mathrm{p}}$ and $f$ by the standard equation

$$
W_{\text {clas }}\left(B_{\mathrm{p}}, f\right)=\frac{2}{6} \times d^{2} B_{\mathrm{p}}^{2} f,
$$

where $d$ is the thickness of the lamination and $\sigma$ is the material conductivity. $W_{\text {clas }}, 5 \%$ decreased upon cold-rolling, is the same in all the deformed and heat treated samples. The assumption of uniform induction must be dropped at sufficiently high frequencies [10], where the skin effect cannot be disregarded. In particular, Eq. (1) tends to overestimate $W_{\text {clas, }}$, at low $B_{\mathrm{p}}$ values (e.g., at $B_{\mathrm{p}}=$ $0.5 \mathrm{~T}$ and $1.0 \mathrm{~T}$ in the present case), while the opposite occurs at high inductions [19]. In such a case, analytical methods can only provide a rough estimate of $W_{\text {clas }}$ in a real non-linear hysteretic material. We shall not deal here with such a problem and we will only identify the upper frequency limit for the confident use of Eq. (1).

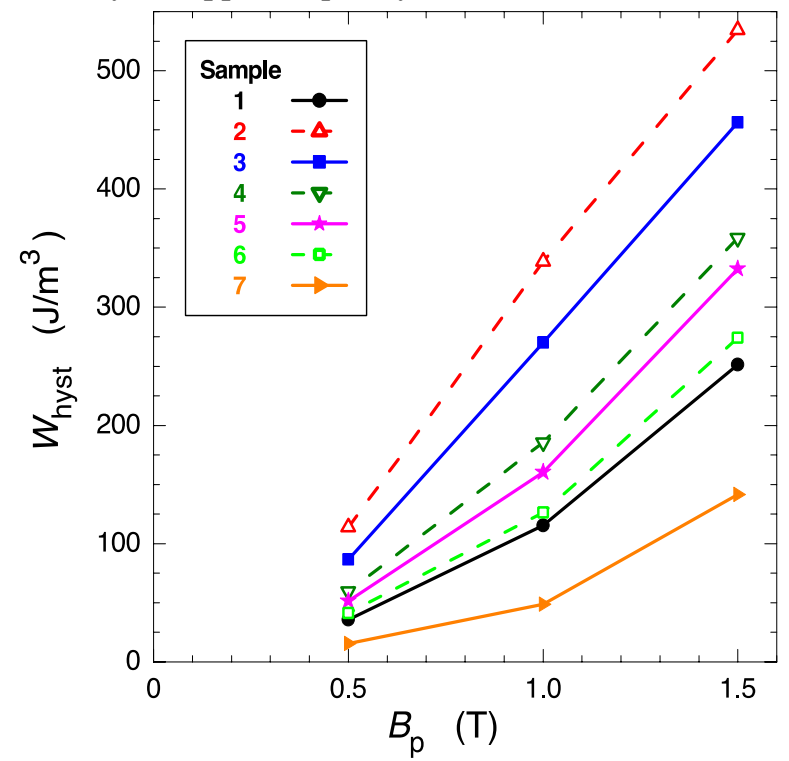

Fig. 3. Hysteresis loss $W_{\text {hyst }}$ as a function of the peak induction $B_{\mathrm{p}}$ in the investigated samples. Recovery proceeds from sample 2 to $6\left(T_{\mathrm{a}}=800{ }^{\circ} \mathrm{C}\right)$, where it is nearly completed, while the final annealing at $T_{\mathrm{a}}=850^{\circ} \mathrm{C}$ brings about recrystallization and further drop of $W_{\text {hyst }}$. 


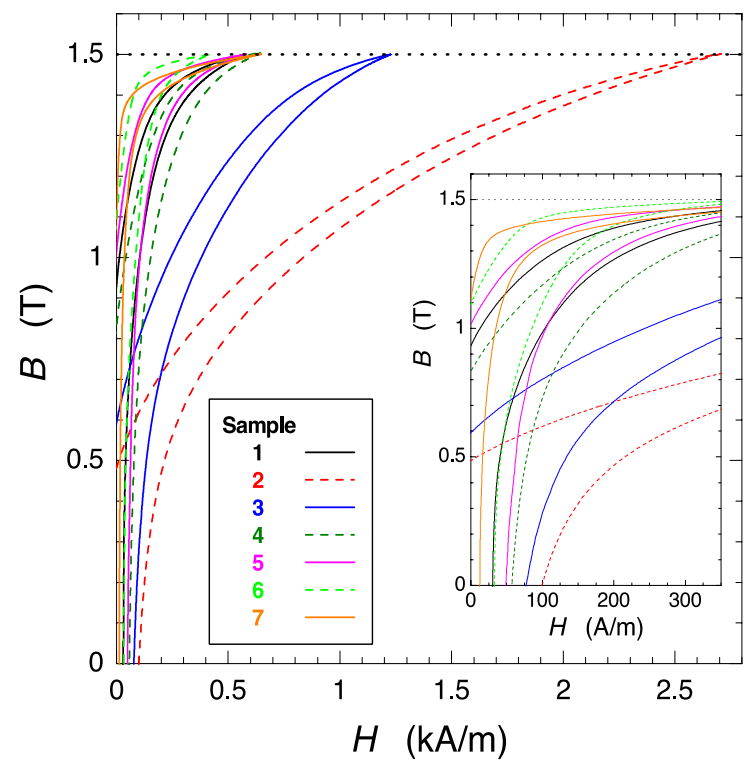

Fig. 4. Hysteresis cycles measured at the frequency $f=2 \mathrm{~Hz}$ and peak induction $B_{\mathrm{p}}=1.5 \mathrm{~T}$. The shape of the curves reflects not only the role of domain wall pinning by the dislocations, but also the magnetoelastic interaction of the magnetization with the random residual stresses, which can favor the alignment of the magnetization along easy axes far from the direction of the applied field.

Excess loss: The excess loss $W_{\text {exc }}$ is experimentally obtained by subtracting the sum of classical and hysteresis components to the measured loss $W$

$$
W_{\text {exc }}\left(B_{\mathrm{p}}, f\right)=W\left(B_{\mathrm{p}}, f\right) \quad W_{\text {clas }}\left(B_{\mathrm{p}}, f\right) \quad W_{\text {hyst }}\left(B_{\mathrm{p}}\right) .
$$

It is predicted by the Statistical Theory of Losses (STL) [10], which identifies a correlation length for the local magnetization reversals and an associated correlation region, defined as "Magnetic Object" (MO), whose threshold field for reversal is statistically distributed in the sample cross-section. The full formulation for $W_{\mathrm{exc}}$ under sinusoidal induction is expressed as [16]

$$
\begin{aligned}
& W_{\mathrm{exc}}\left(B_{\mathrm{p}}, f\right)=2 n_{\mathrm{o}} V_{\mathrm{o}} B_{\mathrm{p}} \\
& \times{ }_{0}^{/ 2}\left(\sqrt{1+\frac{8 G S V_{\mathrm{o}}}{n_{\mathrm{o}}^{2} V_{\mathrm{o}}^{2}} f B_{\mathrm{p}} \cos } \quad 1\right) \cos \mathrm{d},
\end{aligned}
$$

where $G=0.1356$ and the parameters of the model are the products $n_{\mathrm{o}} S$ and $V_{\mathrm{o}} S . n_{\mathrm{o}}$ is the number of MOs simultaneously reversing their magnetization within the cross-sectional area $S$ under quasi-static excitation and $V_{\mathrm{o}}$ is related to the statistical distribution of the local threshold fields [10]. Both $n_{\mathrm{o}}$ and $V_{\mathrm{o}}$ depend on $B_{\mathrm{p}}[16]$. Eq. (3) predicts a $\left(V_{0}^{1 / 2} f^{1 / 2}\right)$ dependence at frequencies such that the quantity $16 \sigma G S B_{\mathrm{p}} f / n_{0}^{2} V_{0} \gg 1$, a condition generally fulfilled above a few $\mathrm{Hz}$ in $\mathrm{NO}$ steel sheets [16]. The experimental dependence of $W_{\text {exc }}$ on $f^{1 / 2}$, obtained applying Eq. (2) for $B_{\mathrm{p}}=1.5 \mathrm{~T}$ and using Eq. (1) for $W_{\text {clas, }}$, is shown for all samples in Fig. 5 (symbols). The results are in excellent agreement with the behavior predicted by Eq. (3) (dashed lines) up to a frequency of the order of $300-400 \mathrm{~Hz}$, depending on the treatment sustained by the sample. The divergence between calculated and predicted $W_{\text {exc }}(f)$ in the upper frequency range are signaling the advent of skin effect, with Eq. (1) falling short of a correct description of $W_{\text {clas. }}$. Remarkably, Fig. 5 shows that the excess loss is the smallest in the deformed sample and increases upon recovery, to eventually approach the behavior displayed by the undeformed sample. Similar conclusions can be made analyzing the $W_{\text {exc }}(f)$ curves at lower $B_{\mathrm{p}}$ values. We have therefore to deal with an opposite response to cold rolling and recovery annealing by the structure-dependent static and dynamic loss components. The increase of the short-range and long-range fluctuations of the magnetoelastic energy upon cold working has the obvious effect of increasing coercive field $H_{\mathrm{c}}$ and hysteresis loss $W_{\text {hyst }}$, with the reverse occurring when smoothing out such fluctuations by the recovery treatment. But, according to the STL, $W_{\text {exc }}$ will depend on the range of the threshold (coercive) fields spanned in activating the MOs, with $V_{0}$ the involved parameter. To simplify the matter, we can assume a uniform distribution of such fields up to $H_{\mathrm{c}, \max }$ and write $V_{0}=H_{\mathrm{c}, \max } / N$, if $N$ is the total number of MOs in the sample cross-section. The balance between $H_{\mathrm{c}, \max }$ and $N$ will determine the evolution of $V_{0}$, that is, of $W_{\text {exc. }}$ Looking then at the results shown in Fig. 6, we conclude that the increase of $N$ outweighs the role of $H_{\mathrm{c}, \max }$ in the cold-worked sheet, resulting in a decrease of $W_{\text {exc }}$ by the decrease of $V_{0}$. The residual short range stresses of alternating signs are expected to engender the fragmentation of the correlation regions, by randomizing the directions of the 


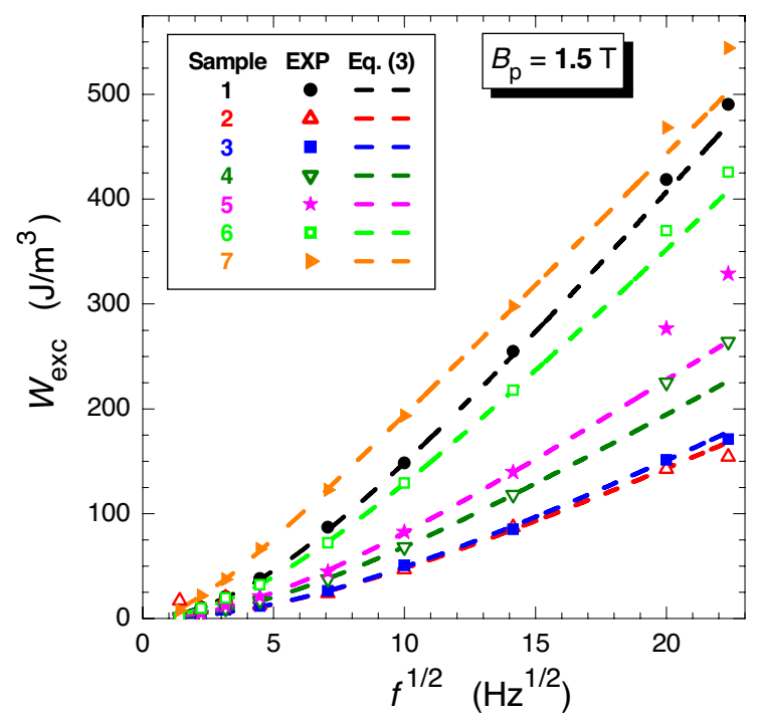

Fig. 5. Excess loss $W_{\text {exc }}$ as a function of the square root of frequency for peak induction $B_{\mathrm{p}}=1.5 \mathrm{~T}$. The symbols show $W_{\text {exc }}$ calculated by Eq. (2), with $W_{\text {hyst }}$ obtained by extrapolating $W(f)$ to $f \rightarrow 0$ and $W_{\text {clas }}$ given by Eq. (1). The dashed lines are predicted by Eq. (3).

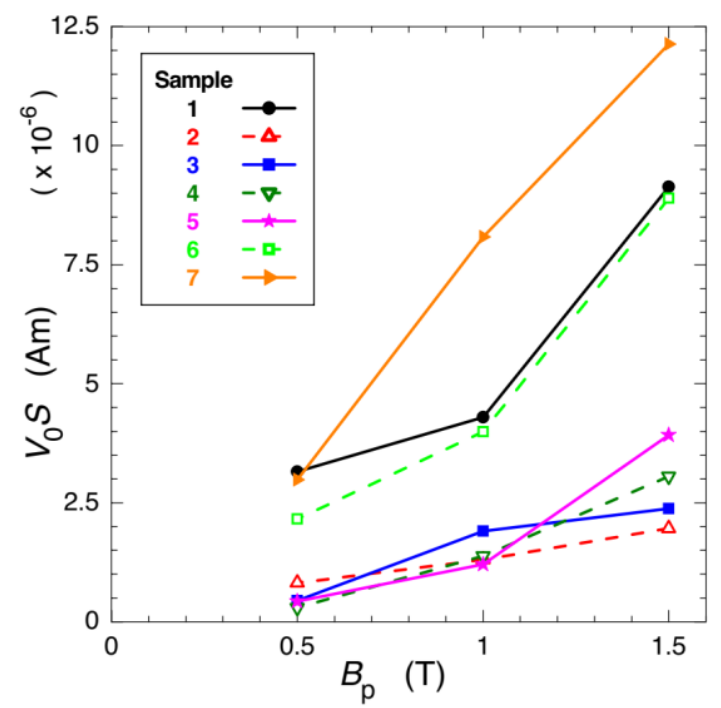

Fig. 6. Excess loss parameter $V_{\mathrm{o}}\left(B_{\mathrm{p}}\right) \cdot S$ and its evolution upon cold rolling and the recovery treatment.

occupied easy axes. This effect is attenuated, but it is preserved on the thermally treated samples.

\section{B. Barkhausen noise analysis}

The Barkhausen noise power spectrum $S(f)$ of the induced signal has been measured in samples 1, 2, and 3 making use of a spectrum analyzer, as described in [20]. The experiments have been performed by exciting the strip between $\pm 1.3 \mathrm{~T}$ at the very low frequency $f=10 \mathrm{mHz}$. A triangular induction waveform was imposed and the noise was analyzed in the frequency interval $[10 \mathrm{~Hz}-100 \mathrm{kHz}]$. The obtained spectra are shown in Fig. 7. It is noted the crossover of the spectral density curves following the cold-rolling treatment.

The theory accounts for the clustering effect of the elementary magnetization reversals and predicts the following expression for the power spectrum [20]

$$
S(f)=4 \dot{\Phi} \cdot \Delta \bar{\Phi}_{c} \frac{1}{1+\left(v_{g} / 2 \pi\right)^{2} / f^{2}} \frac{1}{1+f^{2}\left(2 \pi \rho \tau_{0}\right)^{2}},
$$

where $\dot{\Phi}$ and $\Delta \bar{\Phi}_{c}$ are the controlled macroscopic flux rate and the flux variation associated with a Barkhausen jump cluster, respectively. $v_{\mathrm{g}}$ is the average number of clusters per unit time and $\rho \tau_{0}$ is the average duration of a cluster, being $\rho$ and $\tau_{0}$ the average number of elementary Barkhausen pulses in a cluster and $\tau_{0}$ their mean time separation.

The spectra $S(f)$ in Fig. 7, interpreted through Eq. (4), show how the clustering is affected by the plastic deformation. This equation shows in fact that $S(f)$ is decreased at low frequencies, because the average size of the clusters $\Delta \bar{\Phi}_{c}$ is decreased, implying 
an increase of their number in unit time $v \mathrm{~g}$. This is consistent with the previously stated fragmentation of the correlation regions brought about by cold working. According to Eq. (4), the spectral density at high frequencies $\left(f>>1 / 2 \pi \rho \tau_{0}\right)$ can be written as

$$
S(f)=4 \dot{\Phi} \cdot \frac{1}{4 \pi^{2} \rho \tau_{0}} \cdot \frac{\Delta \bar{\Phi}}{\tau_{0}} \cdot \frac{1}{f^{2}},
$$

putting in evidence its $1 / f^{2}$ behavior and its dependence on the amplitude of the elementary Barkhausen jumps $\Delta \bar{\Phi}$. The highfrequency portion of the spectrum reflects the fine structure of the noise, that is, the elementary jumps and their sequence in the avalanche. Higher coercivities translate into larger elementary magnetization transitions. The high-frequency portion of $S(f)$ is therefore consistent with the evolution of $W_{\text {hyst }}$.

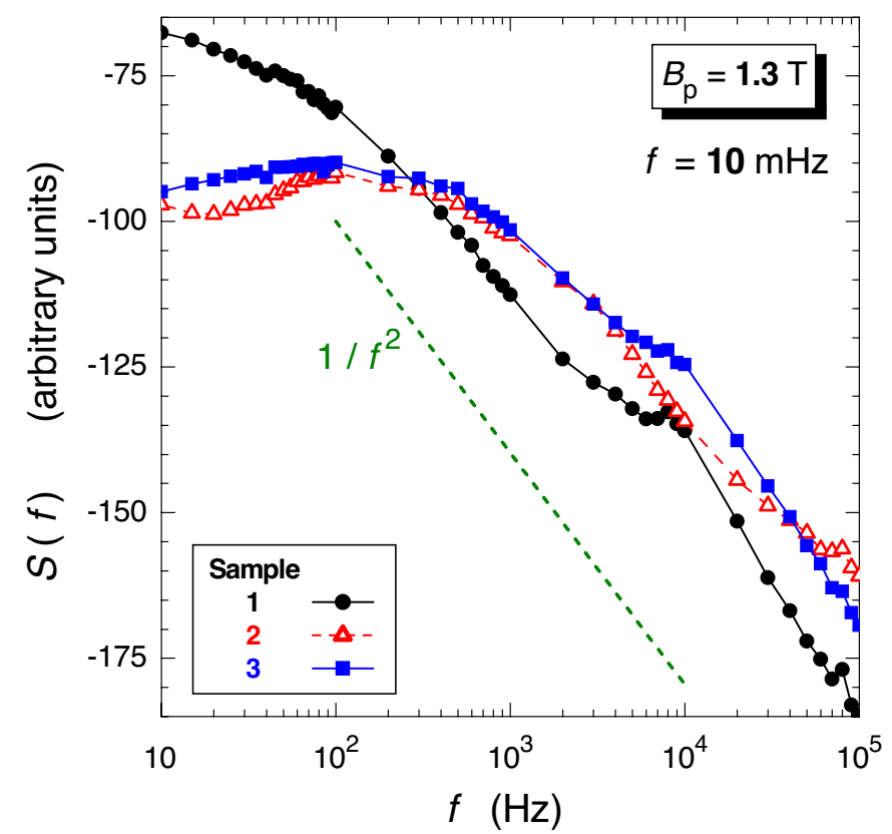

Fig. 7. The Barkhausen noise power spectrum $S(f)$, with $f$ the spectral frequency, is taken at constant induction rate $\mathrm{d} B / \mathrm{d} t=5.2 \cdot 10^{-2} \mathrm{~T} / \mathrm{s}$ between \pm 1.3 T. $S(f)$ responds to plastic deformation by a decrease at low frequencies and an increase at high frequencies.

\section{CONCLUSIONS}

Non-oriented Fe-Si sheets cold-reduced by a few percent, exhibit energy losses decreased with respect to the starting material at intermediate frequencies when subjected to a heat treatment leading to partial recovery. The final improvement of the material occurs because a condition can be reached where the detrimental effect on the hysteresis loss component is overcompensated by the decrease of the excess loss component, ensuing from a fragmentation of the process of reversal of the magnetization. This phenomenon is conveniently and quantitatively assessed by the Statistical Theory of Losses and the related concept of correlation regions, which highlight the cooperative mechanism of the magnetization process.

\section{AKNOWLEDGEMENTS}

FJGL thanks CNPq grant and the support of APERAM and Waelzholz Brasmetal.

\section{REFERENCES}

[1] Electrical steels for e-mobility [online]. Available: https://www.voestalpine.com/isovac/en/Fields-of-application/E-mobility.

[2] powercore ${ }^{\circledR}$ for e-mobility and high frequencies [online]. Available: https://www.thyssenkrupp-steel.com/en/products/electrical-steel/electrical-steel-nongrain-oriented/powercore-for-high-frequencies-and-e-mobility/powercore-a-3.html.

[3] Chun-Kan Hou, Sanboh Lee, "Effect of rolling strain on the loss separation and permeability of lamination steels" IEEE Trans. On Mag., 30 (1994) 212216. DOI: $10.1109 / 20.312260$

[4] V. Permiakov, L. Dupré, A. Pulnikov, and J. Melkebeek, "Loss separation and parameters for hysteresis modelling under compressive and tensile stresses", JMMM, 272-276, (2004) E553-E554. DOI: 10.1016/j.jmmm.2003.11.381

[5] F.J.G. Landgraf, M. Emura, K. Ito, P.S.G. Carvalho. "Effect of plastic deformation on the magnetic properties of non-oriented electrical steels", JMMM, 215/216 (2000) 94-96. DOI: 10.1016/s0304-8853(00)00075-5.

[6] M. Küpferling, C. Appino, V. Basso, G. Bertotti, F. Fiorillo, and P. Meilland, "Magnetic hysteresis in plastically deformed low-carbon steel laminations," J. Magn. Magn. Mater, 316 (2007) e854, doi:10.1016/j.jmmm.2007.03.120

[7] D. L. Rodrigues, J. R. F. Silveira, G. J. L. Gerhardt, F. P. Missell, F. J. G. Landgraf, R. Machado, and M. F. de Campos, "Effect of plastic deformation on the excess loss of electrical steel", IEEE Trans. On Mag., 48 (2012) 1425-1428. DOI: 0.1109/TMAG.2011.2174214 
[8] R. Sato Turtelli, S. Hartl, R. Grössinger, R. Wöhrnschimmel, D. Horwatitsch, F. Pieckermann, G. Polt, and M. Zehetbauer. "Hysteresis and Loss Measurements on the Plastically Deformed Fe-(3 wt\%)Si Under Sinusoidal and Triangular External Field", IEEE Trans. On Mag., 52 (2016) paper 6301007. DOI: 10.1109/TMAG.2016.2530683

[9] Daniel Luiz Rodrigues, Jr, Thomas S. Pascoto Nishikawa, Adriano A. Almeida, Fernando J. G. Landgraf, and Ramon V. Martin, “The Effect of Recovery Annealing on the Magnetic and Mechanical Properties of Nonoriented Electrical Steels", IEEE Trans. On Mag., 50, (2014) paper 2002204. DOI: 10.1109/TMAG.2013.2289734

[10] G. Bertotti, "General properties of power losses in soft ferromagnetic materials", IEEE Trans. On Mag., 24 (1998) 621-630. DOI: DOI: 10.1109/20.43994

[11] Burke JE, Turnbull D. "Recrystallization and grain growth". Progress in Metal Physics (1952) 3:220-292. London: Pergamon Press.

[12] Paulo Rangel Rios, Fulvio Siciliano Jr., Hugo Ricardo Zschommler Sandim, Ronald Lesley Plaut, Angelo Fernando Padilha, "Nucleation and growth during recrystallization", Mat. Res. 8 (2005) 225-238. DOI: 10.1590/s1516-14392005000300002

[13] O. de la Barrière, C. Ragusa, M. Khan, C. Appino, F. Fiorillo, and F. Mazaleyrat, "A simple compensation method for the accurate measurement of magnetic losses with a single strip tester", IEEE Trans. On Mag., 52 (2016) 1-4. DOI: 10.1109/TMAG.2016.2527829

[14] F. Fiorillo, "Measurement and characterization of magnetic materials", North-Holland, 2004.

[15] C. Ragusa and F. Fiorillo, "A three-phase single sheet tester with digital control of flux loci based on the contraction mapping principle", JMMM, 304 (2006) e568-e570, 2006. DOI: 10.1016/j.jmmm.2006.02.177

[16] E. Barbisio, F. Fiorillo, and C. Ragusa, "Predicting Loss in Magnetic Steels Under Arbitrary Induction Waveform and With Minor Hysteresis Loops", IEEE Trans. On Mag., 40 (2004) 1810-1819. DOI: 10.1109/TMAG.2004.830510.

[17] L.J. Swartzendruber, G.E. Hicho, H.D. Chopra, S.D. Leigh, G. Adam, and E. Tsory, "Effect of plastic strain on magnetic and mechanical properties of ultralow carbon sheet steel,” J. Appl. Phys. 81 (1997) 4263-4265. DOI: 10.1063/1.364796.

[18] B. Astie', J. Degauque, J.L. Porteseil, and R. Vergne, "Influence of the dislocation structures on the magnetic and magnetomechanical properties of highpurity iron,” IEEE Trans. Magn. 17 (1981) 2929-2931. DOI: 10.1109/TMAG.1981.1061496.

[19] C. Appino, G. Bertotti, D. Binesti, O. Bottauscio, M. Chiampi, J.P. Ducreux, F. Fiorillo, M. Repetto, and P. Tiberto: "Power losses in thick steel laminations with hysteresis", J. Appl. Phys. 79 (1996) 4575 - 4577. DOI: 10.1063/1.361873.

[20] F. Fiorillo, M. Küpferling, and C. Appino, "Magnetic Hysteresis and Barkausen Noise in Plastically Deformed Steel Sheets", Metals, 8 (2017) 15. DOI: $10.3390 /$ met 8010015 . 